\title{
EFFECT OF TRIGGER POINT INJECTION VS ULTRASONIC THERAPY VS TRANSCUTANEOUS ELECTRICAL NERVE STIMULATION IN REHABILITATION OF CERVICAL AND PERI-SCAPULAR MYOFASCIAL PAIN SYNDROME- A RANDOMIZED CLINICAL TRIAL
}

\author{
Piyali Mondal' ${ }^{1}$ Manomohan Biswas², Jayanta Saha³, Asoke Kumar Middhya ${ }^{4}$
}

${ }^{1}$ Senior Resident, Department of Physical Medicine and Rehabilitation, Bankura Sammilani Medical College, Bankura, West Bengal, India.

${ }^{2}$ Senior Consultant, Department of Physical Medicine and Rehabilitation, Sambhunath Pandit Hospital, Kolkata, West Bengal, India. ${ }^{3}$ Consultant, Department of Physical Medicine and Rehabilitation, Sambhunath Pandit Hospital, Kolkata, West Bengal, India. ${ }^{4}$ Associate Professor, Department of Physical Medicine and Rehabilitation, Bankura Sammilani Medical College, West Bengal, India. ABSTRACT

\section{BACKGROUND}

Myofascial Pain Syndrome (MPS) is a major cause of musculoskeletal pain in the shoulder neck region in modern era, originating from Myofascial Trigger Points (MTrPs) in skeletal muscle, either alone or in combination with other pain generators.

The objectives of this study were- 1. to compare the efficacy and outcome of 3 different treatment modalities namely ultrasound therapy (UST), transcutaneous electrical nerve stimulation (TENS) and steroid mixed with local anaesthetics injection to trigger points, in the clinical outcome of MPS and 2. to propose steps for early rehabilitation after identifying area needing clinical research.

\section{MATERIALS AND METHODS}

Based on the Travell and Simon's criteria, 109 patients diagnosed to have MPS in the cervical and peri scapular region were recruited for this study. They were randomly divided into 3 groups. Group A received ultrasound therapy (UST), group B received transcutaneous electrical nerve stimulation (TENS) and group C received depot form of steroid (Triamcinolone $20 \mathrm{mg}$ ) injection with local anaesthetics (lidocaine $2 \%$ ) at trigger points (TPI). All patients also received therapeutic exercises (Stretching exercis es of trapezius muscle, strain/ counter strain exercise of cervical and upper back), hot packs application and tablet amitriptyline (10 mg) daily at night for 6 weeks. They were followed up after initial visit, at 2nd week, 6th week, 12th week and at 24th week. Pain and result of the treatment were assessed with visual analogue scale (VAS) scores, number of trigger points, index of MTrPs and neck disability index (NDI) questionnaire method.

\section{RESULTS}

Pain scores improved in the patients of all the 3 groups, in the early visits but gradually worsened in later visits. Group C showed significant improvement ( $p$ value $<0.01$ ) in the pain scores by VAS scale and other scores like number of trigger points, MTrP index score and neck disability index score as compared to group A and B. But no group could show significant improvement in outcome measures at long term follow up.

\section{CONCLUSION}

MPS can be effectively managed by TPI. UST and TENS are also approved methods of treatment, but their efficacy is not as remarkable as TPI. But the improvements were sustained for a short term only.

\section{KEY WORDS}

MPS: Myofascial Pain Syndrome, MTrPs: Myofascial Trigger Points, UST: Ultrasound Therapy, TENS: Transcutaneous Electrical Nerve Stimulation, TPI: Trigger Point Injection, LTR: Local Twitch Response.

HOW TO CITE THIS ARTICLE: Mondal P, Biswas M, Saha J, et al. Effect of trigger point injection vs ultrasonic therapy vs transcutaneous electrical nerve stimulation in rehabilitation of cervical and peri-scapular myofascial pain syndrome- a randomized clinical trial. J. Evolution Med. Dent. Sci. 2019;8(07):430-436, DOI: 10.14260/jemds/2019/95

\section{BACKGROUND}

Myofascial pain syndrome is one of the causes of neck pain characterised by MTrPs, found in taut band of muscle bellies. They are small and sensitive foci in muscle that spontaneously or upon compression, cause pain to a distal region, known as referred pain zone along with local twitch response.

'Financial or Other Competing Interest': None.

Submission 31-12-2018, Peer Review 01-02-2019,

Acceptance 07-02-2019, Published 18-02-2019.

Corresponding Author:

Asoke Kumar Middhya,

Vill: Mill More, Kotulpur, Bankura-722141,

West Bengal, India.

E-mail: middhya.asoke14@gmail.com

DOI: $10.14260 /$ jemds $/ 2019 / 95$
MPS has a high prevalence among individuals with regional pain complaints to the extent of $30 \%$. In general orthopaedic clinic, $21 \%$ of all patients are due to MPS.[1] The wide varieties of effective management techniques are available with indication of clinical usefulness of each.[2] It includes manual therapies i.e. stretching, trigger point pressure relief, therapeutic exercises, Physical modalities i.e. thermotherapy, transcutaneous electrical nerve stimulation (TENS) or needling which can be dry or with use of steroids or anaesthetics or botulinum toxin. This study was a humble attempt to compare the roles and efficacy of different physical modalities and local infiltration of steroid at trigger points in cervical and peri-scapular myofascial pain syndrome. 


\section{Objectives of The Study}

1. To compare the efficacy and outcome of three different treatment variation like ultrasound therapy (UST), transcutaneous electrical nerve stimulation (TENS) and local steroid injection to trigger points in the clinical outcome of Myofascial pain syndrome and

2. To propose steps for early rehabilitation and identify the area needing further clinical research.

\section{MATERIALS AND METHODS}

The study design used was a prospective, single-centred, parallel designed, randomized clinical trial which was reviewed and approved by Research Evaluation committee and the institutional Ethical Committee. Information was given comprehensively, both orally and in written form in their own language, to the patients. Written informed consent was obtained prior to their inclusion. The trial was initiated by the investigators and funded by an internal hospital grant. No drug or medical company had any involvement in drug supply, trial conduct or manuscript review. Since the duration of the study was less. The number of patients were taken for convenience.

The study was conducted on recruited patients attaining outpatient department in Physical medicine and
Rehabilitation department in a city-based government tertiary hospital at Kolkata, India. Duration of this study was 16 months from December 2012 to May 2014. Total 120 patients were recruited in this study; among them 40 patients were included in each three groups. Patients was determined after reviewing various journals analysis. $[3,4,5]$

Subjects who fulfilled the Inclusion criteria was 1) Age between 18 and 60 years, 2) Trigger points in the neck \& shoulder region, which disturb normal daily activities for at least 3 months, 3) Reproduction of patient's pain by palpation of trigger points, 4) The number of trigger points was less than 10 . Subjects were excluded from the trial if they were 1) Cervical disc herniation or cervical spine fracture or any other bony abnormalities (Congenital or traumatic), 2) Pregnant, breastfeeding or women planning conception during the study, 3) Poorly controlled Diabetes mellitus, 4) Bleeding diathesis, local or systemic infection \& allergy to anaesthetic agents, insensitive skin or other dermatological diseases, 5) Malignancy, local infection, mechanical implants etc., 6) any hereditary deficiencies. Randomization was done by selecting computer generated random number tables.

Total number of patients included in our study is 109 out of 120 patients. From group A 36, group B 34 and group C 39 patients was missing after first visit. [Fig. 1]

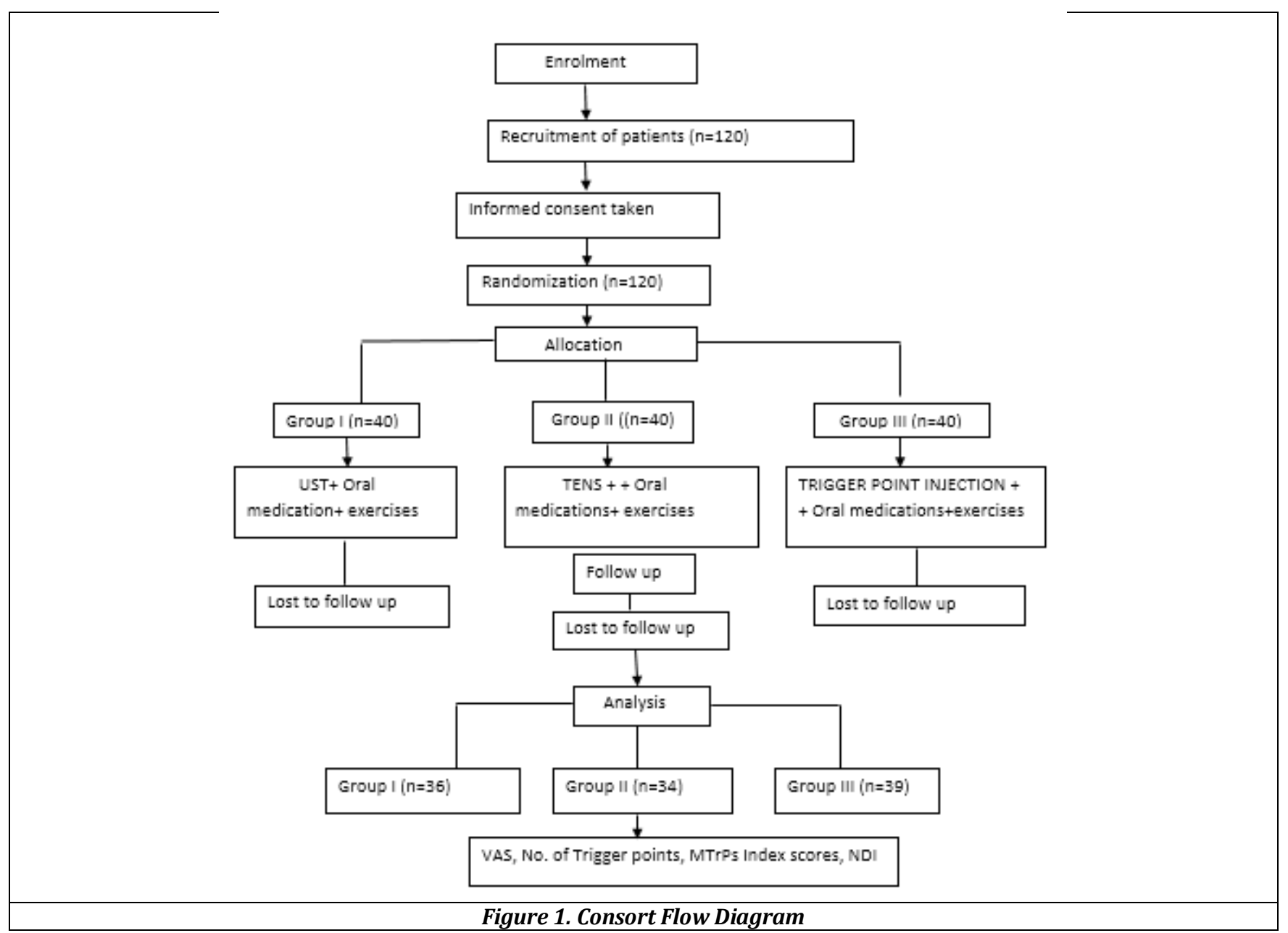

\section{Group A}

Allocated patients received Ultrasonic therapy (Continuous mode, frequency $-1 \mathrm{MHz}$, intensity- $1.5 \mathrm{~W} / \mathrm{cm}^{2}$ ). Total given dose varied depending on how many MTrPs found with treatment time of each trigger point of 5 minutes for 14 days. ${ }^{6]}$ Therapeutic exercises (Spray and Stretch technique to 
manually release trigger points and home exercise program), superficial heat application and concomitant oral medications was received along with the trial.

\section{Group B}

Local heat application, therapeutic exercises, oral medication and transcutaneous electrical nerve stimulation (TENS) (Pulsed mode, frequency - 70-80 Hz, 100-110 microsecond duration) maximum of 14 sessions varied depending on the number of MTrPs with 20 minutes each trigger point per session for 2 weeks.[7]

\section{Group C}

Patients received local trigger point injection (TPI) of $0.5 \mathrm{ml}$ of triamcinolone acetonide depot preparation $(40 \mathrm{mg})$ and diluted with $(0.25 \%)$ lidocaine without adrenalin (Total $2 \mathrm{ml}$ ) along with superficial heat application, therapeutic exercises, oral medication. Each session of TPI was given once per week for a total of 2 weeks.[1] All three groups received Hot Packs at $75^{\circ} \mathrm{C}$ for 20 minutes and Active Stretching exercises, [8] along with use of vapo-coolant spray(Spray and Stretch technique to manually release trigger points) and home exercise program and low dose tab Amitriptyline (10 mg),[4] along with proposed treatment (UST, TENS or Trigger point injection).

\section{Trial Regimen and Procedures}

All patients were fully informed of the possible adverse effects of different physical modalities and trigger point injection and other medications were used in the trial prior to participation.

\section{Exercise Protocol}

The home training programme for the neck exercises focused on strength and mobility for the neck and shoulder region. The programme also included stretching of the involved muscle after hot pack application. Subjects in all three groups were instructed to do stretching exercises of trapezius muscle according to involvement followed by neck isometric exercises. [3]

\section{Spray and Stretch Technique to Manually Release Trigger Points[9] \\ The patient neck is side bended in sitting position, i.e. head toward the opposite side shoulder with the subject in position for stretch the first sweep of jet stream of vaporized coolant spray applied before any stretch pressure is applied in parallel sweeps in one direction over the entire length of the muscle in direction of referred pain pattern from $15 \mathrm{~cm}$ away from skin with not more than 2 or 3 sweeps, the therapist simultaneously stretches the involved muscle.[10] Home exercises were advised to continue for total treatment session. $[9]$}

\section{Hot Packs[8]}

Standardized hot pack was used and applied for 20 minutes over the shoulder as to cover the upper trapezius muscle in supine lying position before starting the session.

\section{Ultrasound Therapy (UST)}

All the patients of group A are being treated with ultrasound therapy. A calibrated ultrasound machine was used for treatment purpose. Ultrasound probe was applied with circular motion that completes one circle in $2 \mathrm{sec}$ with tight circle enough to produce a small overlap of circle with the trigger point in center of the circle. The parameters were 1.5 watt/ $\mathrm{cm}^{2}$ at $3 \mathrm{MHz}$, continuous mode for 5 minutes at each trigger points per session. Total given dose varied depending on how many MTrPs found with treatment time of each trigger point of 5 minutes for 14 days. [6]

\section{Transcutaneous Electrical Nerve Stimulation (TENS)}

Group B patients are being treated with transcutaneous electrical nerve stimulation (TENS) therapy. After skin exposure, the negative electrode of TENS unit was placed on the trigger point of the trapezius muscle, and the positive electrode was placed in the direction of long axis of same dermatome of that muscle.[11] The current was applied at a pulse mode, frequency of 70-80 $\mathrm{Hz}$ and duration $100-110$ $\mu \mathrm{s}$; the intensity was set at a level that each subject could feel but that was not strong enough to induce muscle contraction. The current was applied for 25 minutes at each trigger point.

\section{Trigger Point Injection Procedure}

All the patients of group $\mathrm{C}$ are being treated with trigger point injection.[12]

\section{Pre-Injection}

Iincreased bleeding tendencies should be explored before injection. Capillary haemorrhage augments post injection soreness and leads to unsightly ecchymosis.[13] Patients should refrain from daily aspirin dosing for at least three days before injection to avoid increased bleeding. While the patient was in a sitting position, the trigger point area was determined, and the skin was cleaned with an appropriate antiseptic solution. Local injections were performed according to the technique previously described by Travell and Simons.[13] When a trigger point (MTrP) was located and the overlying skin was cleansed with alcohol, the point was immobilized between the thumb and index finger or index and middle finger. Using sterile technique, 21-gauge, 2-inch needle then was inserted 1 to $2 \mathrm{~cm}$ away from the MTrP, so that the needle could be advanced into the MTrP at an acute angle of $30^{\circ}$ to the skin. To ensure that the needle was not within a blood vessel, the plunger was withdrawn before injection. A small amount $(0.2 \mathrm{~mL})$ of anaesthetic was injected when the needle encountered a tiny sensitive locus when a LTR response was elicited and then withdrawn. 1 to 2 $\mathrm{ml}$ of solution containing depot preparation of triamcinolone acetonide $(20 \mathrm{mg}$ ) with $0.25 \%$ lignocaine without adrenaline was injected. The needle then was withdrawn to the level of the subcutaneous tissue and redirected in all direction and was repeated according to number of trigger points.[14,15]

\section{Data Collection}

The primary outcome was measured using following outcome measures and documented at initial and subsequent visits-

1. Assessment of subjective pain intensity measured using visual analogue scale (VAS) between 0 and 10 . 
participants were asked to rate their average pain during the last 24 hours out of 10 , with 0 representing no pain and 10 representing the worse pain imaginable.[16]

2. Physician palpated the number of trigger points at each visit (MTrPs).[16,17]

3. Index score of MTrPs: After palpating the MTrPs, marked the size, consistency and tenderness, using a score from 0 to 3.

0 : indicating increased consistency but where palpation produced no pain

1: increased consistency but patient indicating only pain after being asked

2: increased consistency and the patient spontaneously expressed pain

3: increased consistency and the patient withdrew from palpation (jump sign).

An index score[16] was made from the sum of the scores at each treatment session. The total number of MTrPs and index scores was used as effect variables.

4. Functional disability was assessed with neck disability Index (NDI) items score range from 0 to 5 , higher score indicated greater disability. [18,19]

\section{Statistical Analysis}

Statistical analysis was done by SPSS version 15 for analysing the collected data. Results on continuous measurements are presented as mean \pm SD and results on categorical measurements are presented in number. Student's ' $t$ ' test was used for comparison of continuous data between two groups.
Proportions were analysed by the use of the Chi-square test or Fisher's test. Results were considered statistically significant if $\mathrm{p}<0.05$, highly significant if $\mathrm{p}<0.001$ and not significant if $p>0.05$

\section{RESULTS \\ Demographic Characteristics}

Incidence of MPS was more in males than females. In group A, incidence among females and males were $72.2 \%$ and $27.8 \%$, in group B, $76.5 \%$ and $23.5 \%$ and in group C, it was $87.2 \%$ and $12.8 \%$. $\mathrm{P}$ values of comparison between group $\mathrm{A}$ and $\mathrm{B}$ was 0.684 , group $A$ and $C$ was 0.106 and between group $B$ and $C$ was 0.233 . In this study, mean age of presentation was $32.8 \pm 7.308$ in group A, $36.26 \pm 10.387$ in group B and 35.36 \pm 10.449 in group C. VAS scores for pain intensity measurement was significantly improved after treatment at visit 2 in all the groups but more profoundly in group $C$ with $P$ value $<0.001$ when compared with visit 1 . Mean of number of trigger points and Index score of MTrPs were decreased in subsequent visits ( $\mathrm{p}$ value $<0.001$ ) compared to initial visit [Table 3, 4]. Statistically significant improvement seen in NDI on 2 nd visit onward with $\mathrm{p}$ value $<0.001$ compared to initial visit; but 4 th and 5 th visit scores were again increased. $P$ value of VAS scores, Number of trigger points, MTrP index score and in NDI in different visits (Between A, B and C Groups) were showed significant improvement in post treatment visits with $\mathrm{p}$ value $<0.001$ for all 3 groups. But trigger point injection was superior than other 2 groups [Refer Table 3, 4, 5, 6].

\begin{tabular}{|c|c|c|c|c|c|c|c|}
\hline Group & N & Mean & Std. Error of Mean & Median & Std. Deviation & \multicolumn{2}{c|}{ Quartiles } \\
\hline & & & & & & Lower & Upper \\
\hline A & 36 & 32.83 & 1.218 & 32 & 7.308 & 28 & 36 \\
\hline B & 34 & 36.26 & 1.781 & 35.5 & 10.387 & 29 & 43.25 \\
\hline C & 39 & 35.36 & 1.673 & 32 & 10.449 & 28 & 45 \\
\hline \multicolumn{7}{|r}{} \\
\hline
\end{tabular}

\begin{tabular}{|c|c|c|c|}
\hline & A vs B & A vs C & B vs C \\
\hline $\mathrm{p}$ Value & 0.113 & 0.233 & 0.712 \\
\hline \multicolumn{2}{|c|}{ Table 1 } \\
\hline
\end{tabular}

\begin{tabular}{|c|c|c|c|c|c|c|c|c|}
\hline \multirow[t]{2}{*}{ Sex } & \multirow[t]{2}{*}{ Variables } & \multicolumn{3}{|c|}{ Group } & \multirow[b]{2}{*}{ Total } & \multicolumn{3}{|c|}{ p Value } \\
\hline & & $\mathbf{A}$ & B & C & & A VS. B & A VS. C & B VS. C \\
\hline Female & Number & 26 & 26 & 34 & 86 & \multirow{3}{*}{0.684} & \multirow{3}{*}{0.106} & \multirow{3}{*}{0.233} \\
\hline & $\%$ & 72.2 & 76.5 & 87.2 & 78.9 & & & \\
\hline Male & Number & 10 & 8 & 5 & 23 & & & \\
\hline & $\%$ & 27.8 & 23.5 & 12.8 & 21.1 & & & \\
\hline Total & & $\begin{array}{c}36 \\
(100)\end{array}$ & $\begin{array}{c}34 \\
(100)\end{array}$ & $\begin{array}{c}39 \\
(100)\end{array}$ & $\begin{array}{c}109 \\
(100)\end{array}$ & & & \\
\hline
\end{tabular}

\begin{tabular}{|c|c|c|c|c|c|c|}
\hline & \multicolumn{3}{|c|}{ Group } & \multirow{2}{*}{\multicolumn{3}{|c|}{ p Value }} \\
\hline & UST & TENS & $\begin{array}{c}\text { Trigger } \\
\text { Point Inj. }\end{array}$ & & & \\
\hline & Mean \pm Std. Deviation & Mean \pm Std. Deviation & Mean \pm Std. Deviation & \begin{tabular}{|l|} 
A VS. B \\
\end{tabular} & A VS. C & B VS. C \\
\hline VAS Visit 1 & $7.25 \pm 0.91$ & $7.26 \pm 0.9$ & \begin{tabular}{|l|l|}
$7.38 \pm 0.91$ \\
\end{tabular} & \begin{tabular}{|l|}
0.946 \\
\end{tabular} & 0.523 & 0.573 \\
\hline VAS Visit 2 & $3.06 \pm 1.31$ & $3.26 \pm 1.08$ & $1.59 \pm 0.5$ & 0.470 & $<0.001$ & $<0.001$ \\
\hline VAS Visit 3 & $3.69 \pm 1.26$ & $4.32 \pm 0.84$ & $1.87 \pm 0.73$ & 0.017 & $<0.001$ & $<0.001$ \\
\hline
\end{tabular}




\begin{tabular}{|c|c|c|c|c|c|c|}
\hline VAS Visit 4 & $4.81 \pm 1.31$ & $5 \pm 1.04$ & $2.64 \pm 0.99$ & 0.495 & $<0.001$ & $<0.001$ \\
\hline VAS Visit 5 & $5.94 \pm 1.22$ & $6.15 \pm 1.13$ & $4.13 \pm 1.22$ & 0.474 & $<0.001$ & $<0.001$ \\
\hline p Value Visit 1 vs. Visit 2 & $<0.001$ & $<0.001$ & $<0.001$ & & & \\
\hline p Value Visit 1 vs. Visit 3 & $<0.001$ & $<0.001$ & $<0.001$ & & & \\
\hline p Value Visit 1 vs. Visit 4 & $<0.001$ & $<0.001$ & $<0.001$ & & & \\
\hline p Value Visit 1 vs. Visit 5 & $<0.001$ & $<0.001$ & $<0.001$ & & & \\
\hline
\end{tabular}

Table 3. Comparison of Numerical Variables and p Values VAS Scores Between Different Visits and Between the Three Groups

\begin{tabular}{|c|c|c|c|c|c|c|}
\hline & \multicolumn{3}{|c|}{ Group } & \multirow{2}{*}{\multicolumn{3}{|c|}{ p Value }} \\
\hline & \multirow{2}{*}{$\begin{array}{c}\text { UST } \\
\text { Mean } \pm \text { Std. Deviation }\end{array}$} & \multirow{2}{*}{$\begin{array}{c}\text { TENS } \\
\text { Mean } \pm \text { Std. Deviation }\end{array}$} & \multirow{2}{*}{\begin{tabular}{|c|} 
Trigger Point INJ \\
Mean \pm Std. Deviation \\
\end{tabular}} & & & \\
\hline & & & & A VS. B & A VS. C & B VS. C \\
\hline No. of Trigger Points Visit 1 & $3.53 \pm 0.94$ & \begin{tabular}{|l|}
$3.59 \pm 0.99$ \\
\end{tabular} & \begin{tabular}{|l|}
$3.85 \pm 1.16$ \\
\end{tabular} & \begin{tabular}{|l|}
0.794 \\
\end{tabular} & \begin{tabular}{|l|}
0.198 \\
\end{tabular} & 0.314 \\
\hline No. of Trigger Points Visit 2 & $2.5 \pm 1.06$ & $2.85 \pm 0.82$ & $1.97 \pm 0.9$ & 0.125 & 0.023 & $<0.001$ \\
\hline No. of Trigger Points Visit 3 & $2.61 \pm 1.02$ & $2.88 \pm 0.81$ & $2 \pm 0.89$ & 0.224 & 0.007 & $<0.001$ \\
\hline No. of Trigger Points Visit 4 & $2.86 \pm 1.05$ & $3.12 \pm 0.98$ & $2.15 \pm 0.88$ & 0.294 & 0.002 & $<0.001$ \\
\hline No. of Trigger Points Visit 5 & $2.94 \pm 0.96$ & $3.38 \pm 1.02$ & $2.72 \pm 0.97$ & 0.067 & 0.313 & 0.006 \\
\hline p Value Visit 1 vs. Visit 2 & $<0.001$ & $<0.001$ & $<0.001$ & & & \\
\hline p Value Visit 1 vs. Visit 3 & $<0.001$ & $<0.001$ & $<0.001$ & & & \\
\hline p Value Visit 1 vs. Visit 4 & $<0.001$ & $<0.001$ & $<0.001$ & & & \\
\hline p Value Visit 1 vs. Visit 5 & $<0.001$ & 0.017 & $<0.001$ & & & \\
\hline
\end{tabular}
the Three Groups

\begin{tabular}{|c|c|c|c|c|c|c|}
\hline & \multicolumn{3}{|c|}{ Group } & \multirow{2}{*}{\multicolumn{3}{|c|}{ p Value }} \\
\hline & \multirow{2}{*}{$\begin{array}{c}\text { UST } \\
\text { Mean } \pm \text { Std. } \\
\text { Deviation } \\
\end{array}$} & \multirow{2}{*}{$\begin{array}{c}\text { TENS } \\
\text { Mean } \pm \text { Std. } \\
\text { Deviation }\end{array}$} & \multirow{2}{*}{$\begin{array}{c}\text { Trigger } \\
\text { Point Inj. } \\
\text { Mean } \pm \text { Std. } \\
\text { Deviation } \\
\end{array}$} & & & \\
\hline & & & & A VS. B & A VS. C & B VS. C \\
\hline MTrPs Index Score Visit 1 & $8.11 \pm 2.72$ & $8.65 \pm 2.53$ & $9.33 \pm 2.6$ & 0.398 & 0.050 & 0.259 \\
\hline MTrPs Index Score Visit 2 & $3.86 \pm 1.76$ & $4.65 \pm 1.94$ & $2.77 \pm 1.29$ & 0.080 & 0.003 & $<0.001$ \\
\hline MTrPs Index Score Visit 3 & $4.22 \pm 1.61$ & $5.38 \pm 1.83$ & $3 \pm 1.36$ & 0.006 & 0.001 & $<0.001$ \\
\hline MTrPs Index Score Visit 4 & $5.14 \pm 2.19$ & $6.29 \pm 2.1$ & $3.46 \pm 1.54$ & 0.028 & $<0.001$ & $<0.001$ \\
\hline MTrPs Index Score Visit 5 & $6.22 \pm 2.4$ & $7.38 \pm 2.39$ & $5 \pm 2$ & 0.047 & 0.019 & $<0.001$ \\
\hline P Value Visit 1 vs. Visit 2 & $<0.001$ & $<0.001$ & $<0.001$ & & & \\
\hline P Value Visit 1 vs. Visit 3 & $<0.001$ & $<0.001$ & $<0.001$ & & & \\
\hline P Value Visit 1 vs. Visit 4 & $<0.001$ & $<0.001$ & $<0.001$ & & & \\
\hline P Value Visit 1 vs. Visit 5 & $<0.001$ & $<0.001$ & $<0.001$ & & & \\
\hline
\end{tabular}

Table 5. Comparison of Numerical Variables and p Value of MTrPs Index Score Between Three Different Groups and Different Visits

\begin{tabular}{|c|c|c|c|c|c|c|}
\hline & \multicolumn{3}{|c|}{ Group } & \multirow{2}{*}{\multicolumn{3}{|c|}{ p Value }} \\
\hline & \multirow{2}{*}{\begin{tabular}{|c|} 
UST \\
Mean \pm Std. \\
Deviation \\
\end{tabular}} & \multirow{2}{*}{\begin{tabular}{|c|} 
TENS \\
$\begin{array}{c}\text { Mean } \pm \text { Std. } \\
\text { Deviation }\end{array}$ \\
\end{tabular}} & \multirow{2}{*}{$\begin{array}{c}\text { Trigger } \\
\text { Point Inj. } \\
\text { Mean } \pm \text { Std. } \\
\text { Deviation }\end{array}$} & & & \\
\hline & & & & A VS. B & A VS. C & B VS. C \\
\hline Neck Disability Index (NDI) Score VISIT 1 & $48.99 \pm 7.64$ & $49.6 \pm 7.98$ & $49.72 \pm 7.59$ & 0.746 & 0.683 & 0.951 \\
\hline Neck Disability Index (NDI) Score VISIT 2 & $17.03 \pm 7.31$ & $21.53 \pm 9.34$ & $10.29 \pm 4.58$ & 0.028 & $<0.001$ & $<0.001$ \\
\hline Neck Disability Index (NDI) Score VISIT 3 & $21.59 \pm 8.35$ & $28.62 \pm 9.03$ & $11.36 \pm 5.02$ & 0.001 & $<0.001$ & $<0.001$ \\
\hline Neck Disability Index (NDI) Score VISIT 4 & $29.93 \pm 9.92$ & $33.71 \pm 9.05$ & $15.26 \pm 5.28$ & 0.102 & $<0.001$ & $<0.001$ \\
\hline Neck Disability Index (NDI) Score VISIT 5 & $37.76 \pm 11.03$ & $42.44 \pm 8.09$ & $27.32 \pm 9.41$ & 0.048 & $<0.001$ & $<0.001$ \\
\hline P Value Visit 1 vs. Visit 2 & $<0.001$ & $<0.001$ & $<0.001$ & & & \\
\hline P Value Visit 1 vs. Visit 3 & $<0.001$ & $<0.001$ & $<0.001$ & & & \\
\hline P Value Visit 1 vs. Visit 4 & $<0.001$ & $<0.001$ & $<0.001$ & & & \\
\hline P Value Visit 1 vs. Visit 5 & $<0.001$ & $<0.001$ & $<0.001$ & & & \\
\hline Different & $\begin{array}{l}\text { dp Values } \\
\text { Between } t\end{array}$ & $\begin{array}{l}\text { f Neck Disa } \\
\text { Three Grou }\end{array}$ & Index & & & \\
\hline
\end{tabular}

\section{DISCUSSION}

In current medical practice Myofascial Pain Syndrome has becoming a real rehabilitation challenge in our society. Multiple treatment options are available now in the hands of clinicians preclude any standardized management, which can be practiced for every patient of MPS. This clinical trial aimed to compare the efficacy of three treatment approaches for MPS. Here, Incidence among females was more than males, mostly were desk job sedentary worker. Friction et al[20] and Drewes et al[21] were also found female predominance than male. According to SK Severino et al, some hormonal changes attributing to MPS in females and pain was reported to 
increase during second week of menstrual period.[22] Anette Kaergaard et al[23] assessed the occurrence of two restrictively defined neck-shoulder disorders among sewing machine operators among 243 patients where job involves monotonous, highly repetitive tasks performed in a sitting working posture with upper back curve and head bent over the sewing machine. Es Rachlin[24] said, occupational or recreational activities that produce repetitive stress on a specific muscle or muscle group commonly cause chronic stress in muscle fibres, leading to trigger points due to improper body mechanics. The primary goal of management for MPS is to break the vicious cycle of pain through elimination of trigger points. A multi-disciplinary approach is required in managing MPS. [25] Physical therapy, exercise, ischemic compression, heat, stretch and spray technique, local injections with local anaesthetics, steroid or dry needling and pharmacological treatment are all used for management of MTrPs.[16,24,25] Anthony H. Wheeler,[26] Frost et al [27] proved trigger point injection is one of the most effective methods ${ }^{[26]}$ for treatment of MPS. It is performed by different means as dry needling or local anaesthetics, steroids etc. In this study the trigger point injection was superior to ultrasound therapy or TENS in the treatment of cervical and peri-scapular MPS for short term pain relief. Tablet Amitriptyline $(10 \mathrm{mg}$ ) is also used here. The 6-week and 1year effectiveness of low dose amitriptyline (10-30 mg) showed a significant reduction of pain scores. ${ }^{[4]}$ NDI score was used in outcome measure which proved greater disability reduction with group C patients in our trial. J Sarrafzadeh et al [28] and Majlesi and Unalan [29] have proved effectiveness of UST in management of MPS. Eriksson et al [30] stated burst TENS were more effective than conventional one. Group A and B patients have shown significant improvement in all parameters in $2 \mathrm{nd}, 3 \mathrm{rd}, 4$ th and $5^{\text {th }}$ visit with $\mathrm{p}$ value $<0.001$ as compared to 1 st visit. From the mean value of each visit, it is observed that, more improvement occurred at post treatment 1st and 2nd visit, but 3rd visit onwards, improvement was less than immediate previous visits. In other words, although the patients got significant relief from their painful condition after treatment with UST or TENS, but this improvement was more marked up to 2 to 6 weeks from the treatment. Chuen-Ru Hou et al[5] proposed that TENS alone is not useful treating modality for MTrPs; it can be used as a secondary technique when combined with other therapeutic exercises to increase cervical ROM. Cold spray and release of taut bands by stretching was helpful for pain relief in our study. TM Cummings [31] and J C King et al [32] stated that trigger point injection is one of the most effective methods among other managements. TA Garvey et al [33] used four different types: lidocaine, lidocaine combined with a steroid, acupuncture, and vapo-coolant spray with acupressure for trigger point management. Results indicated that therapy without injected medication (63\% improvement rate) was as effective as therapy with drug injection ( $42 \%$ improvement rate).[35] Needling technique actually break contraction knots suggested by Simon[13] and ultimately disrupt vicious cycle. Ay $\mathrm{S}$ et al also used local anaesthetic injection ( $2 \mathrm{ml}$ lidocaine of $1 \%$ ) and dry injection on trigger points. No significant differences were observed between the groups ( $p>0.05$ ).[34] Summarizing the effect of trigger point injection with lidocaine combined with steroid, in this present study, group $\mathrm{C}$ showed that VAS Scores decreased significantly in $2 \mathrm{nd}, 3 \mathrm{rd}$ and $4^{\text {th }}$ visits. (Refer Table no 2, 3, 4, 5 , Figure 1). Lignocaine was acted as short term pain relief [35] and steroid played as anti-inflammatory agent by aborting upregulation of arachidonic acid pathway.[36] In our study, when we compared the improvement of VAS scores, number of trigger points and index scores of trigger points and NDI between different groups, improvement with trigger point injection was greater than UST and TENS group. Effectiveness of UST and TENS is more or less similar in our trial. Although UST, TENS and TPI have proven effectiveness in management of MPS but TPI was preferred because improvement was more than UST and TENS. But it has to be admitted that regardless of the mode of treatment be it UST or TENS or TPI, satisfactory relief from the pain of cervical and peri-scapular MPS is short lived, mainly up to 6 weeks. Long term effectiveness (up to 24 weeks/ 6 months) is not much pronounced albeit a significant improvement statistically.

\section{Limitations}

Limitation was the effect of treatment duration. Long term treatment sessions may be necessary to prolong the benefit. Another limitation was less number of participant recruitment. Further randomised controlled trials are needed to validate the safety and effectiveness of multiple treatment sessions by trigger point injection therapy.

\section{CONCLUSION}

Single injection at trigger point or use of other physical modalities for small period of time is not helpful enough and only gives short term relief. Multiple treatment sessions may be required to prolong the effectiveness of the treatment modality long term. The efficacy of the treatment is more significant up to 6 weeks ( $p$ value $<0.001$ ). In long term follow up (24 weeks), no treatment options, among the three groups in our study, could prove their effectiveness.

\section{REFERENCES}

[1] Borg-Stein J. Treatment of fibromyalgia, myofascial pain and related disorders. Phys Med Rehabil Clin N Am 2006;17(2):491-510.

[2] Hong CZ. Muscle pain syndrome. In: Braddom RL, Chan L, Harrast MA, et al. eds. Physical medicine \& rehabilitation. $4^{\text {th }}$ edn. Philadelphia: Elsevier Saunders 2011: p. 974.

[3] Ay S, Doğan SK, Evcik D, et al. Comparison of the efficacy of phonophoresis and ultrasound therapy in myofascial pain syndrome. Rheumatol Int 2011;31(9):1203-8.

[4] Plesh O, Curtis D, Levine J, et al. Amitriptyline treatment of chronic pain in patients with temporomandibular disorders. J Oral Rehabil 2000;27(10):834-41.

[5] Hong CZ. Lidocaine injection versus dry needling to myofascial trigger point: the importance of the local twitch response. Am J Phys Med Rehabil 1994;73(4):256-63.

[6] Watson T, Young SR. Therapeutic ultrasound. In: Watson $\mathrm{T}$, edr. Electrotherapy evidence-based practice. $12^{\text {th }}$ edn. Edinburgh: Churchill Livingstone/ Elsevier 2008: p. 179-97. 
[7] Kruger LR, Van der Linden WJ, Cleaton-Jones PE. Transcutaneous electrical nerve stimulation in the treatment of myofascial pain dysfunction. S Afr J Surg 1998;36(1):35-8.

[8] Chandola HC, Chakraborty A. Fibromyalgia and myofascial pain syndrome - a dilemma. Indian J Anaesth 2009;53(5):575-81.

[9] Travell JG, Simons DG. Myofascial pain and dysfunction: the trigger point manual. Vol. 2. Baltimore, MD: Williams \& Wilkins 1992.

[10] Travell JG, Simons DG. Myofascial pain and dysfunction: the trigger point manual. Vol. 1. Baltimore, MD: Williams \& Wilkins 1983.

[11] Tekin L, Akarsu S, Durmuş 0, et al. The effect of dry needling in the treatment of myofascial pain syndrome: a randomized double-blinded placebocontrolled trial. Clin Rheumatol 2013;32(3):309-15.

[12] Hardman JG, Limbard LE. Goodman \& Gilman's The pharmacological basis of therapeutics. $10^{\text {th }}$ edn. New York: McGraw-Hill Publishers 2001: p. 451-77.

[13] Simons DG, Travell JG, Simons LS. Travell \& Simons' Myofascial pain and dysfunction: the trigger point manual. Vol. 1. 2nd edn. Baltimore: Williams \& Wilkins 1999: p. 11-93.

[14] Childers MK, Simons DG. Botulinum toxin use in myofascial pain syndromes. In: Lennard TA, edr. Pain procedures in clinical practice. $2^{\text {nd }}$ edn. Philadelphia: Hanley \& Belfus 2000: p. 191-202.

[15] Alvarez DJ, Rockwell PG. Trigger points: diagnosis and management. Am Fam Physician 2002;65(4):653-61.

[16] Gam AN, Warming S, Larsen LH, et al. Treatment of myofascial trigger-points with ultrasound combined with massage and exercise - a randomised controlled trial. Pain 1998;77(1):73-9.

[17] Rayegani SM, Bayat M, Bahrami MH, et al. Comparison of dry needling and physiotherapy in treatment of myofascial pain syndrome. Clin Rheumatol 2014;33(6):859-64.

[18] Iqbal A, Khan SA, Miraj M. Efficacy of ischaemic compression technique in combination with strain counterstrain technique in managing upper trapezius myofascial trigger point pain. Indian J Physiother \& Occup Ther 2010;4(2):10-5.

[19] Lew HL, Lee EH, Castaneda A, et al. Therapeutic use of botulinum toxin type A in treating neck and upperback pain of myofascial origin: a pilot study. Arch Phys Med Rehabil 2008;89(1):75-80.

[20] Friction JR, Kroening R, Haley D, et al. Myofascial pain syndrome of the head and neck: a review of clinical characteristics of 164 patients. Oral Surg Oral Med Oral Pathol 1985;60(6):615-23.

[21] Drewes AM, Jennum P. Epidemiology of myofascial pain, low back pain, morning stiffness and sleep related complaints in the general population. J Musculoskeletal Pain 1995;3(Suppl 1):G8.
[22] Severino SK, Moline ML. Premenstrual syndrome. Obstet Gynecol Clin North Am 1990;17(4):889-903.

[23] Kaergaard A, Anderson JH. Musculoskeletal disorders of the neck and shoulders in female sewing machine operators: prevalence, incidence and prognosis. Occup Environ Med 2000;57(8):528-34.

[24] Rachlin ES. Trigger points. In: Rachlin ES, edr. Myofascial pain and fibromyalgia: trigger point management. St. Louis: Mosby 1994: p. 145-57.

[25] Kamanli A, Kaya A, Ardicoglu 0, et al. Comparison of lidocaine injection, botulinum toxin injection and dry needling to trigger points in myofascial pain syndrome. Rheumatol Int 2005;25(8):604-11.

[26] Wheeler AH, Goolkasian P, Gretz SS, et al. Botulinum toxin A for the treatment of chronic neck pain. Pain 2001;94(3):255-60.

[27] Frost FA, Jessen B, Siggaard-Andersen J. A control, double-blind comparison of mepivacaine injection versus saline injection for myofascial pain. Lancet 1980;315(8167):499-501.

[28] Sarrafzadeh J, Ahmadi A, Yassin M. The effects of pressure release, phonophoresis of hydrocortisone, and ultrasound on upper trapezius latent myofascial trigger point. Arch Phys Med Rehabil 2012;93(1):72-7.

[29] Majlesi J, Ünalan H. High-power pain threshold ultrasound technique in the treatment of active myofascial trigger points: a randomized, double-blind, case-control study. Arch Phys Med Rehabil 2004;85(5):833-6.

[30] Eriksson MBE, Sjolund BH, Neilzen S. Long term results of peripheral conditioning stimulation as an analgesic measure in chronic pain. Pain 1979;6(3):335-47.

[31] Cummings TM, White AR. Needling therapies in the management of myofascial trigger point pain: a systematic review. Arch Phys Med Rehabil 2001;82(7):986-92.

[32] King JC, Goddard MJ. Pain rehabilitation. 2. Chronic pain syndrome and myofascial pain. Arch Phys Med Rehabil 1994;75(5 Spec No):S9-14.

[33] Garvey TA, Marks MR, Wiesel SW. A prospective, randomized, double-blind evaluation of trigger-point injection therapy for low-back pain. Spine (Phila $\mathrm{Pa}$ 1976) 1989;14(9):962-4.

[34] Ay S, Evcik D, Tur BS. Comparison of injection methods in myofascial pain syndrome: a randomized controlled trial. Clin Rheumatol 2010;29(1):19-23.

[35] Bisby MA. Inhibition of axonal transport in nerves chronically treated with local anesthetics. Exp Neurol 1975;47(3):481-9.

[36] Collighan N, Gupta S. Epidural steroids. Continuing Education in Anaesthesia, Crit Care Pain 2010;10(1):15. 